01

\title{
Вынужденные колебания углеродной нанотрубки с током эмиссии в электромагнитном поле
}

\author{
(C) С.В. Булярский, ${ }^{1}$ А.А. Дудин, ${ }^{1}$ А.П. Орлов, ${ }^{1}$ А.А. Павлов, ${ }^{1}$ В.Л. Леонтьев ${ }^{2}$ \\ ${ }^{1}$ Институт нанотехнологий микроэлектроники РАН, \\ 119334 Москва, Россия \\ ${ }^{2}$ Ульяновский государственный университет, \\ 432970 Ульяновск, Россия \\ e-mail: bulyar2954@mail.ru
}

(Поступило в Редакцию 2 марта 2017 г.)

Проанализирован процесс возникновения колебаний в одиночной углеродной нанотрубке, в которой протекает постоянный ток автоэлектронной эмиссии и которая помещена в электромагнитное поле. Экспериментально показано, что в нанотрубке кроме постоянного возникает переменная составляющая эмиссионного тока, обладающая резонансом на определенной частоте. Проведены расчеты, которые показывают связь частоты резонанса с параметрами системы и самой нанотрубки. Выполнен анализ условий, при которых резонанс можно сдвинуть в терагерцовый диапазон частот колебаний.

\section{Введение}

Углеродные нанотрубки обладают свойством поглощения и испускания электромагнитного излучения. Это открывает перспективу создания приемно-передающих устройств на их основе $[1,2]$. Данная способность нанотрубок проявляется в широком диапазоне длин волн от радиочастотного до оптического. Контакт углеродной нанотрубки с металлом катализатора выпрямляет [3], что позволяет использовать их в качестве ректен [4]. В связи с этим важно проанализировать условия возникновения колебательных процессов в нанотрубке и характеристики данных процессов.

Применение углеродных нанотрубок в радиоустройствах требует глубокого понимания природы физических свойств этих объектов. В настоящей работе обнаружено и описано физическое явление вынужденных колебаний углеродной нанотрубки в электромагнитном поле. Нанотрубка с током, помещенная в электромагнитное поле высокой частоты, начинает колебаться. При определенной частоте электромагнитного поля колебания нанотрубки испытывают резонанс, при этом амплитуда колебаний возрастает. Эти колебания оказывают влияние на автоэлектронную эмиссию с концов углеродных нанотрубок, находящихся в сильном электрическом поле, возбуждая высокочастотный эмиссионный ток. Это явление открывает перспективы создания усилителей электромагнитных колебаний, работающих на новых принципах.

Цель настоящей работы - выявить связь частотных характеристик системы с механическими параметрами нанотрубки. Это позволит определять указанные параметры с необходимой точностью, что является важным для практического использования радиочастотных свойств углеродных нанотрубок (УНТ).

\section{Экспериментальные результаты}

Для исследований частотных характеристик углеродных нанотрубок как элементов наноэлектроники был создан измерительный стенд и разработаны методики измерений вольт-амперных, эмиссионных и амплитудночастотных характеристик УНТ в высокочастотных электромагнитных полях. Стенд был собран на базе растрового электронного микроскопа FEI HeliosNanoLab 650 DualBeam, позволяющий визуально наблюдать колебания нанотрубки и фиксировать момент резонанса.

В измерительной системе было задействовано три электрода (рис. 1). К катоду 1 крепилась углеродная нанотрубка. Анод 2 позволял измерять вольтамперную характеристику, когда нанотрубка его касалась, и эмиссионную характеристику, когда она была отодвинута от 2-го электрода на расстояние несколько десятков

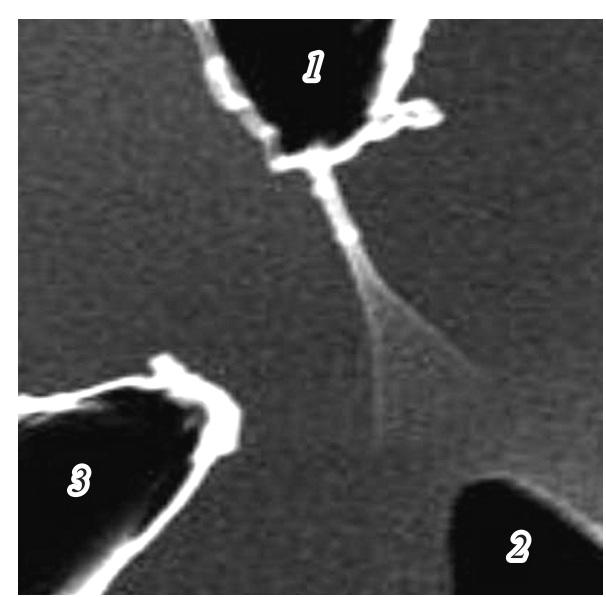

Рис. 1. Изображение исследуемой системы с углеродной нанотрубкой, которая находится в режиме резонанса вынужденных колебаний. 1 - катод с закрепленной нанотрубкой, 2 - анод, 3 - электрод, возбуждающий переменное магнитное поле. 


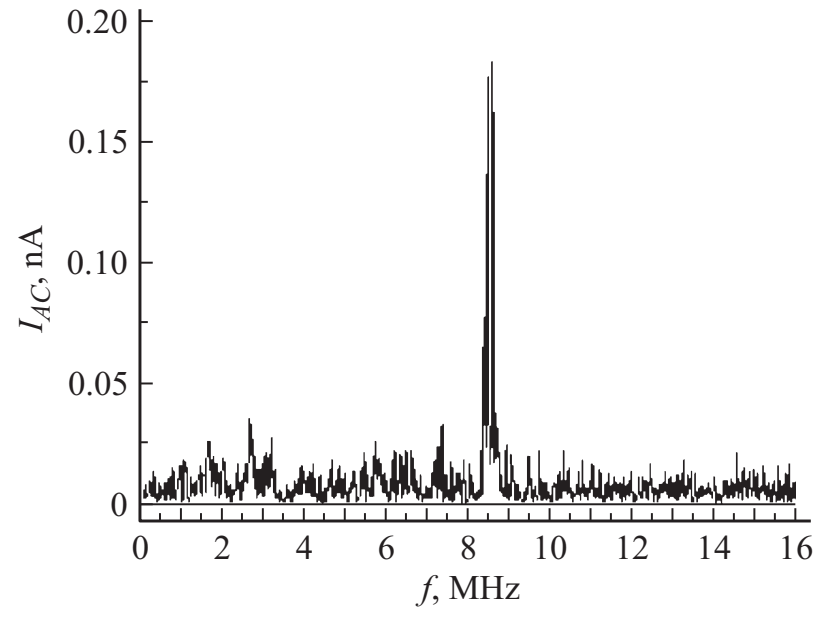

Рис. 2. Экспериментальный частотный спектр колебаний углеродной нанотрубки.

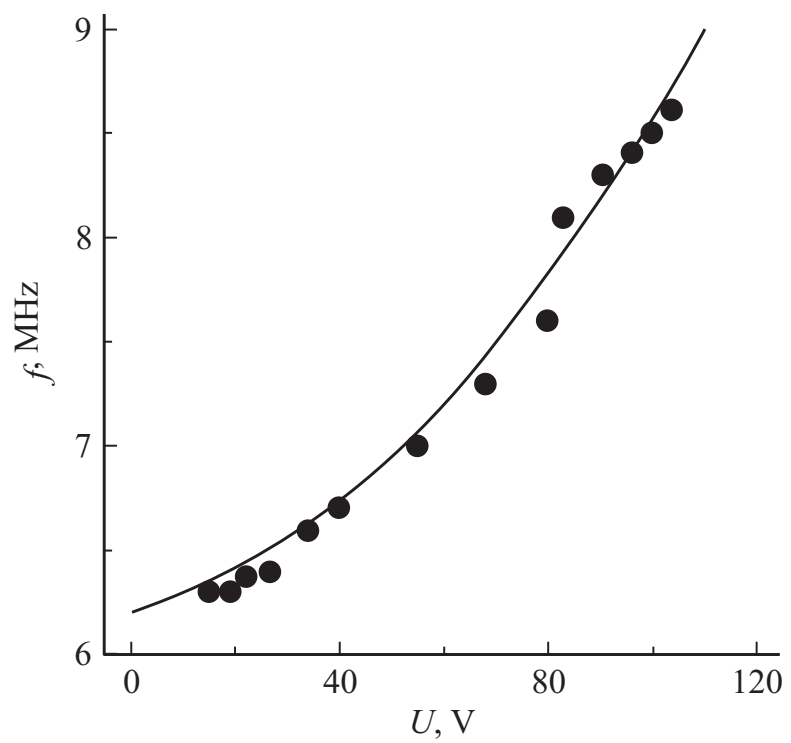

Рис. 3. Зависимость частоты резонанса вынужденных колебаний углеродной нанотрубки от приложенного электрического напряжения между катодом и анодом. Эксперимент - точки. Сплошная линия - расчет по формулам (1) и (2).

нанометров. На электрод 3 подавалось высокочастотное напряжение, которое создавало в пространстве, окружающем нанотрубку, электромагнитное поле.

На рис. 1 зафиксирован момент резонанса колебаний, когда по цепи электрод 1 -нанотрубка-вакуум-электрод 2 протекает постоянный эмиссионный ток с величиной $100 \mathrm{nA}$. Ток, текущий через нанотрубку, взаимодействует с окружающим электромагнитным полем и нанотрубка начинает колебаться. В процессе колебаний расстояние между концом нанотрубки и анодом периодически изменяется. Это вызывает появление в эмиссионном токе переменной составляющей. На рис. 2 показана амплитудно-частотная характеристика этого переменного тока в указанной выше цепи. Полуширина резонансной кривой составляет порядка $0.2 \mathrm{MHz}$, что говорит о достаточно высокой добротности процесса. Частота резонанса зависит от величины эмиссионного тока, а следовательно, и электрического напряжения между электродами 1 и 2 (рис. 3, точки). Это создает возможность управления приемно-передающими свойствами нанотрубки. Величина переменного тока между электродом 3 и катодом очень мала, так как электроды находятся в вакууме и их относительная емкость также мала. Поэтому возникновение переменной составляющей тока эмиссии можно рассматривать как усиление переменного тока определенной частоты. Коэффициент усиления максимален в режиме резонанса, которой можно управлять путем изменения напряжения между катодом и анодом.

\section{Обсуждение результатов}

На проводник с током, помещенным в магнитное поле, действует сила Ампера. В нашем случае эта сила изменяется с частотой вынуждающего сигнала, создаваемого электродом 3. В системе возникают вынужденные колебания. Для описания этого явления используем математическую модель динамического изгиба УНТ, жестко защемленной на одном конце $(x=0)$, свободной от кинематических связей на другом конце $(x=L)$ и нагруженной постоянной продольной силой $F[5]$ :

$$
E J \frac{\partial^{4} W(x, t)}{\partial x^{4}}-F \frac{\partial^{2} W(x, t)}{\partial x^{2}}+\rho S \frac{\partial^{2} W(x, t)}{\partial t^{2}}=q(x, t) .
$$

Это уравнение решается с граничными условиями

$$
W(0, t)=0,\left.\frac{\partial W}{\partial x}\right|_{x=0}=0,\left.\frac{\partial^{2} W}{\partial x^{2}}\right|_{x=L}=0,\left.\frac{\partial^{3} W}{\partial x^{3}}\right|_{x=L}=0 .
$$

Здесь $W-$ прогиб УНТ, $E-$ модуль упругости УНТ, $J$ - момент инерции УНТ, который вычисляется для полой нанотрубки $\left(d_{1}, d_{2}\right.$ - диаметры внутренней и внешней поверхностей нанотрубки), $\rho-$ плотность УНТ, $S$ - площадь поперечного сечения УНТ, $q(x, t)-$ величина поперечной нагрузки, порождаемой электромагнитным полем. Начальные условия не указываются, поскольку исследование модели свелось к анализу свободных колебаний УНТ с указанными граничными условиями.

Для расчета были использованы следующие параметры УНТ: $L=3450 \mathrm{~nm}, d_{1}=55 \mathrm{~nm}, d_{2}=57 \mathrm{~nm}$, $E=10^{11} \mathrm{~Pa}, \rho=2.26 \cdot 10^{3} \mathrm{~kg} / \mathrm{m}^{3}$. Величина растягивающей УНТ продольной силы $F$, действующей на УНТ и определяемой электрическим напряжением между электродами 1 и 2, находилась по формуле [6]

$$
F=\frac{\varepsilon_{0} S_{э л} V^{2}}{2 h^{2}},
$$

где $\varepsilon_{0}=8.85 \cdot 10^{-12} \mathrm{~F} / \mathrm{m}, S_{э л}=1.13 \cdot 10^{-16} \mathrm{~m}^{2}, h-$ pacстояние между электродом 2 и свободным концом УНТ. 


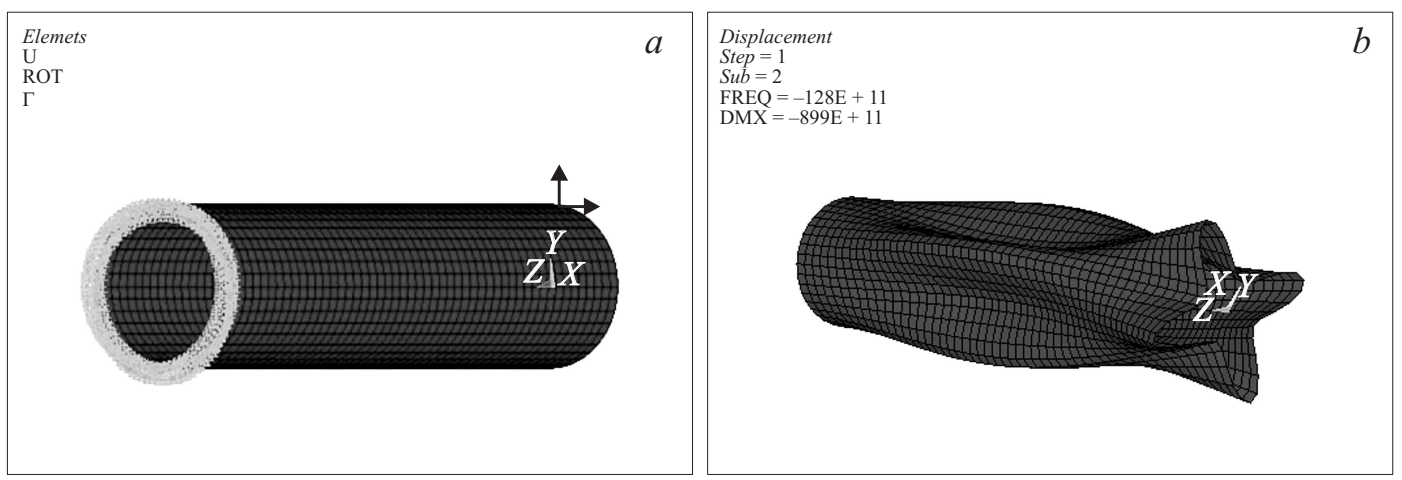

Рис. 4. Результаты расчета колебаний нанотрубки с закрепленным концом с малым аспектным отношением.

Значению $V=110$ соответствует сила $F=18 \cdot 10^{-10} \mathrm{~N}$. В области $\left[0,18 \cdot 10^{-10}\right]$ значений продольной силы $F$ построена равномерная сетка с шагом $3 \cdot 10^{-10}$, содержащая семь узлов и шесть участков. Результаты решения задачи о свободных колебаниях прямолинейной в недеформированном состоянии УНТ, полученного методом конечных элементов, приведено на рис. 3 (сплошная кривая).

На рис. 3 (сплошная линия) приведена зависимость первой частоты свободных колебаний УНТ от электрического напряжения, которое определяет (задает) величину продольной силы. Расчет хорошо согласуется с экспериментом. Некоторое расхождение зависимостей, отображенных на рис. 3, имеется в окрестности точки $V=80 \mathrm{~V}$, в которой в эксперименте наблюдается более резкое нарастание эмиссионного тока и, как следствие, увеличение силы, действующей на УНТ. Сравнение экспериментальных и расчетных результатов рис. 3 показывает, что наблюдаемая зависимость первой частоты свободных механических колебаний УНТ от величины вынуждающей силы является причиной зависимости резонансной частоты тока, протекающего по УНТ, от напряжения между электродами 1 и 2. Расчет показал, что аналогичная зависимость имеется для второй гармоники свободных колебаний УНТ и соответственно для второй резонансной частоты вынужденных колебаний УНТ под действием электромагнитного поля. Частота второго резонанса примерно в 5 раз превышает частоту первого резонанса.

Величиной частоты резонанса можно управлять, изменяя параметры нанотрубки. Особенно она чувствительна к аспектному отношению длины трубки к ее радиусу. При отношении $L / R=2$ можно добиться резонанса в терагерцовом диапазоне. Изменяя аспектное отношение, можно добиться возникновения резонанса на нужной частоте от единиц $\mathrm{MHz}$ до THz.

Резонансная частота чувствительна и к иным параметрам нанотрубки. Уменьшение плотности за счет выращивания коротких двухстенных нанотрубок увеличенного диаметра и повышенного модуля Юнга позволяют достичь частот 5-10 GHz, что подтверждается расчетами методом конечных элементов. Первая и вторая сим- метричные формы свободных колебаний приводятся на рис. 4. Колебания имеют достаточно сложный характер. Расчет вынужденных колебаний УНТ выполнен в рамках оболочечной модели для случая, в котором на свободном краю оболочки действует внешняя гармоническая сила. Вектор силы имеет две ненулевые гармонические составляющие амплитуды $100 \mathrm{~Pa}$, направленные вдоль осей $X$ и $Y$. Отклик на действие этой силы (резонанс), рассмотренный в узле сетки конечных элементов, находящемся посередине той образующей прямой линии цилиндрической срединной поверхности, которая проходит также через точку приложения внешней силы, характеризуется диапазоном от 11 до $12 \mathrm{GHz}$.

Таким образом, методика расчетов в рамках оболочечной модели, позволила вычислить частоты резонанса низшей частоты свободных колебаний УНТ. Этим, во-первых, обоснована возможность использования развитой методики для получения оценок частот свободных колебаний УНТ, во-вторых, обоснована высокая степень достоверности тех результатов исследований свободных колебаний УНТ [7], с которыми проводилось сравнение, в-третьих, показано, что полученные в [7] выводы о возможности реализации $\mathrm{THz}$ механических свободных колебаний УНТ имеют высокую степень достоверности. Следовательно, реализация $\mathrm{THz}$ наноустройств на основе УНТ с использованием механических $\mathrm{THz}$ резонансов УНТ (до 9 THz) возможна. Для создания таких наноустройств, как показывают построенные здесь оценки, следует стремиться к использованию УНТ, у которых аспектное отношение является минимальными из области их возможных (в смысле технической реализации) значений.

Работа выполнена при поддержке РФФИ 17-02-00276 и РНФ.

\section{Список литературы}

[1] Rutherglen C., Burke P. // Nano Lett. 2007. Vol. 7. N 11. P. 3296-3299.

[2] Jensen K., Weldon J., Garcia H., Zettl A. // Nano Lett. 2007. Vol. 7. N 11. P. 3508-3511. 
[3] Булярский С.В., Булярская С.А., Вострецова Л.Н., Дудин А.А., Орлов А.П., Павлов А.А., Басаев А.С., Киџюк Е.П., Шаманаев А.А., Шаман Ю.П. // Наномикросистемная техника. 2015. № 5 (158). С. 3-8.

[4] Kempa K., Rybczynski J., Huang Z., Gregorczyk K. // Adv. Mater. 2007. Vol. 19. P. 421-426.

[5] Вибрации в технике: Справочник. В 6 томах / Ред. совет. предс. В.Н. Челомей. М.: Машиностроение, 1978. Т. 1. Колебания линейных систем / Под ред. В.В. Болотина. 1978. $352 \mathrm{c}$.

[6] Yong Z., Horacio D. // Int. J. RF and Microwave ComputerAided Eng. 2004. Vol. 14. N 4. P. 317-328.

[7] Леонтьев В.Л. // XI Всеросс. съезд по фундаментальным проблемам теоретической и прикладной механики: Сб. докл. Казань: Изд-во Казан. ун-та, 2015. С. 2302-2303. 